\title{
Obstetric Outcomes in Adolescents Related to Body Mass Index and Compared with Low-Risk Adult Women
}

Anna Ramö Isgren, Preben Kjölhede and Marie Blomberg

The self-archived version of this journal article is available at Linköping University Electronic Press:

http:/ / urn.kb.se/ resolve?urn=urn:nbn:se:liu:diva-138265

N.B.: When citing this work, cite the original publication.

Ramö Isgren, A., Kjölhede, P., Blomberg, M., (2017), Obstetric Outcomes in Adolescents Related to Body Mass Index and Compared with Low-Risk Adult Women, J ournal of Women's Health, 26(5), 426-434. https:/ / dx.doi.org/ 10.1089/jwh.2016.5938

Original publication available at:

https:/ / dx.doi.org/ 10.1089/jwh.2016.5938

Copyright: Mary Ann Liebert

http:/ / www.liebertpub.com/ 
Obstetric outcomes in adolescents related to body mass index and compared with low risk adult women

Ramö Isgren A MD, Kjølhede P MD, PhD, Blomberg M MD, PhD

Department of Obstetrics and Gynecology, and Department of Clinical and Experimental Medicine, Linköping University, Linköping, Sweden.

Corresponding author:

Dr. Marie Blomberg

Department of Obstetrics and Gynecology

SE-581 85 Linköping Sweden

E-mail: marie.blomberg@regionostergotland.se

Phone: +46101034957

Running title: BMI and obstetric outcomes in adolescents

Keywords: obstetric outcomes, overweight, obesity, adolescents 


\section{Abstract}

Objective: To evaluate the associations of body mass index (BMI) in adolescents and obstetric outcomes and to determine whether the outcomes in the BMI groups of adolescents differ from that of a low risk population of adult women.

Methods: Nationwide population-based register study. Obstetric outcomes of 31,386 singleton primiparous adolescents were evaluated in relation to BMI classes. Furthermore, the outcomes of the adolescents and 178,844 normal weight, non-smoking, singleton primiparous women, 25-29 years old with no known comorbidity, defined as standard women, were compared. Multiple logistic regression models were used. Results are presented as crude or adjusted odds ratios (OR or aOR) and with a 95\% confidence interval.

Results: Compared with normal weight adolescents, obese adolescents had a lower chance of a normal vaginal delivery (VD) - 76\% vs. 85\% (aOR 0.61 (0.55-0.68)), a higher risk for acute cesarean section - 8.9\% vs. $4.5 \%$ (aOR 2.45 (2.08-2.88)) and stillbirth - 0.7\% vs. $0.2 \%$ (aOR 3.17 (1.74-5.77)). Compared with standard women, overweight adolescents had a higher chance of a normal VD - 82 \% vs. 75\% (OR 1.53 (1.44-1.64)) and a lower risk for acute CS 6.3\% vs. 7.1\% (OR 0.85 (0.76-0.95)). Obese adolescents had a lower risk for instrumental VD - 8\% vs. 13\% (OR 0.61 (0.53-0.71)) and obstetric anal sphincter injury - 1\% vs. 3\% (OR 0.38 (0.26-0.57))

Conclusion: Several adverse obstetric outcomes were obesity-related among adolescents. Overweight adolescents seemed to have better obstetric outcomes than standard women, something to consider when optimizing resources for women during pregnancy and delivery. 


\section{Introduction}

Maternal overweight and obesity are associated with adverse pregnancy and delivery outcomes among adults. ${ }^{1-6}$ Studies have shown that the occurrence of obstetric complications increases in morbidly obese pregnant adults. ${ }^{3-5}$

In adolescents, the associations with obesity and morbid obesity on obstetric outcomes are still relatively unexplored. A few studies that have focused on maternal overweight and obesity among adolescents have shown an increased risk for cesarean section (CS), preeclampsia, induction of labor, gestational diabetes mellitus (DM) and pregnancy-induced hypertension in these weight groups. ${ }^{7-10}$ However, some studies have even shown a positive obstetric effect, with a lower risk for preterm birth with spontaneous onset in both overweight and obese adolescents. ${ }^{9,11,12}$

In 2013, 11\% of all births world-wide were estimated to be given by teenage girls. ${ }^{13}$ During 2009-2010, among female children and adolescents 12-19 years, 33\% were either overweight or obese and $17 \%$ were obese in the US. ${ }^{14}$ The results of studies of teenage pregnancies evaluating obstetric outcomes, compared with adults, are contradictory. Whether adverse obstetric outcomes are the result of biological factors or could be explained by other confounding factors, such as for instance smoking or inadequate prenatal care, have been frequently discussed. ${ }^{15,16}$ A recently published population-based study from Sweden showed better obstetric outcomes among adolescents compared with adults regarding being more likely to have a spontaneous onset of labor and a normal vaginal delivery (VD), having a lower risk for CS, instrumental VD, perineal rupture, major postpartum hemorrhage (PPH) and shoulder dystocia, but had an increased risk for preterm birth. ${ }^{17}$ 
Thus it seems important to more carefully analyze the association between obstetric outcomes in different weight groups of adolescents in order to obtain more accurate information about the associations between overweight and obesity and pregnancy-related issues in adolescents.

When entering the delivery unit a pregnant woman is assessed and an obstetric risk classification is conducted in order to individualize the obstetric care. ${ }^{18}$ Women who are classified as high risk will require more intensive resources. It is of great importance to allocate the limited resources available where given most benefit. One way of grading risk assessments could be to introduce a group of low risk adult women as comparison to other groups with defined obstetric risks.

The aim of this study was to evaluate the associations between maternal body mass index (BMI) in adolescents and obstetric outcomes. In addition to further validate the impact of adolescent overweight and obesity on obstetric outcomes we compared these women with an adult obstetric low risk population. 


\section{Materials and Methods}

This is a nationwide population-based retrospective cohort study of primiparous adolescents with singleton pregnancies, evaluating obstetric outcomes in relation to maternal BMI.

Data from 1992 until 2013, including all primiparous women with singleton pregnancies, were obtained from the Swedish Medical Birth Register (SMBR). SMBR has existed since 1973 and is a national mandatory register, run by the Swedish National Board of Health and Welfare, where more than 98\% of all deliveries in Sweden are registered. Since 1992, the register has included information on maternal weight and height in early pregnancy. The information in the register is collected from standardized prenatal, obstetric and neonatal forms that are used in all maternity healthcare centers, birth units, and at the pediatric examination of the newborn. The register has been described in detail and validated. ${ }^{19-21}$

At the first antenatal visit, which usually occurs during gestational weeks 8-12, the selfreported maternal height and smoking habits are listed and maternal weight is either selfreported or measured. On the same occasion, the midwife registers the pre-pregnancy comorbidity concerning hypertension, DM, asthma, systemic lupus erythematosus, epilepsy and chronic renal disease with a mark in boxes with the pre-written conditions in the antenatal form.

In total, 37,492 primiparous adolescents ( $<20$ years of age) with singleton pregnancies were listed in the SMBR in the period 1992 to 2013. Of these, 31,386 (84\%) were documented with weight and height in early pregnancy. These 31,386 women represented our study group.

The registered details of maternal height and weight in early pregnancy enabled calculation of maternal BMI $\left(\mathrm{kg} / \mathrm{m}^{2}\right)$. The BMI was classified into four BMI subgroups: underweight ( $\left.<18.5 \mathrm{~kg} / \mathrm{m}^{2}\right)$, normal weight (18.5-24.9 kg/m²), overweight (25.0-29.9 kg/m²), and obesity $\left(\geq 30.0 \mathrm{~kg} / \mathrm{m}^{2}\right.$ ). In addition, the obesity group was subdivided into three classes: 
obesity class I (30.0-34.9 kg/m²), obesity class II (35.0-39.9 kg/m²) and obesity class III ( $\geq 40$ $\left.\mathrm{kg} / \mathrm{m}^{2}\right)$.

Furthermore, a group consisting of normal weight (BMI 18.5-24.9 kg/m²), nonsmoking, primiparous women, aged 25 to 29 years, with singleton pregnancies and no prepregnancy systemic comorbidity (hypertension, DM, asthma, systemic lupus erythematosus, epilepsy and chronic renal disease) was selected from the SMBR. In all, 178,844 women fulfilled these criteria. This group was looked upon as representing standard women with a low risk of adverse obstetric outcomes, and was used for comparison of the BMI groups of the adolescents.

The pregnancy outcomes that were studied included preeclampsia, spontaneous onset of labor, induction of labor, gestational age (GA) at delivery (categorized as $<28$ weeks, $<37$ weeks, $\geq 42$ weeks), abruptio placentae, placenta previa and stillbirth. Stillbirth was from 1992 until June 2008, included after 28 weeks of gestation, and from July 2008, included after 22 weeks of gestation. The delivery outcomes that were studied included normal VD (defined as neither instrumental VD nor CS delivery), instrumental VD (including forceps and vacuum extraction), CS (all, and subdivided into elective and acute) and shoulder dystocia.

The SMBR has been extended over time. From 1999 and onwards the CS was registered as elective or acute.

The postpartum outcomes that were studied included obstetric anal sphincter injury (OASI) and PPH >1000 ml (subdivided into CS and VD). PPH has been registered in the SMBR since 1997.

Preeclampsia, abruptio placentae, placenta previa, still birth, shoulder dystocia, and PPH $>1000 \mathrm{ml}$ were all registered in the SMBR as a diagnosis according to The International Statistical Classification of Diseases and Related Health Problems (ICD). Stillbirth was registered either using the ICD 9-codes 7681-2 or as a mark in the box in the standardized 
register form. Preeclampsia was equivalent to the ICD 9-codes 6424-7 and the ICD 10-codes O11, O14 or O15; abruptio placentae was equivalent to the ICD 9-code 6412 and the ICD 10code O45; placenta previa was equivalent to the ICD 9-code 6410-1 and the ICD 10-code O44; shoulder dystocia was equivalent to the ICD 9-code 6604 and the ICD 10-code O66. PPH $>1000$ ml was registered using the ICD 10-code 072 and OASI was registered either as a mark in the pre-written box or as the ICD 9-code 6643-4 and the ICD 10-code O70.2-3. Approval of the study was obtained from the Regional Ethical Review Board in Linköping. (Dnr 2014/369-32)

\section{Statistics}

Data were analyzed by means of logistic regression analysis models for comparison of categorical data. Risk estimates are presented as odds ratios (ORs) with 95\% confidence intervals (95\% CI). In the statistical analyses of BMI groups of adolescents the group of normal weight adolescents was used as the reference group. Crude as well as adjusted ORs are presented. Adjustments were made for smoking in early pregnancy, calendar year of the delivery, maternal age and maternal comorbidity. Preeclampsia and CS were also adjusted for GA and GA for preeclampsia. Shoulder dystocia and OASI were also adjusted for birth weight. In the comparison of the BMI groups of the adolescents with the standard women, the crude ORs are presented.

All statistical analyses were conducted using the software STATISTICA 64 V.12 (StatSoft Inc., 2300 East 14 ${ }^{\text {th }}$ St., Tulsa, Oklahoma 74104, USA). 


\section{Results}

The demographic and descriptive data of the primiparous adolescents according to BMI groups are summarized in Table 1 . The prevalence of overweight adolescents was $19.5 \%$ and obese $7.3 \%$. The prevalence of obesity classes I, II and III were 5.5\%, 1.4\% and $0.4 \%$, respectively. The proportions of smokers were higher among the obese adolescents than among normal weight and overweight adolescents. The prevalence of DM and hypertension registered at the first antenatal visit was low in all BMI groups; however, there seemed to be an increasing trend in prevalence as BMI increased. The occurrence of asthma increased with higher BMI; 8.2\% in the normal weight class and 18.3\% in the obesity class III.

Table 2 shows the prevalence of the obstetric outcomes in the BMI groups of adolescents and the group of standard women.

The results of the multivariate analyses of the obstetric outcomes of the BMI groups of adolescents are presented in Table 3. The group of normal weight adolescents was used as a reference in the analyses of the BMI groups of adolescents.

Spontaneous onset of labor was significant adversely associated with BMI levels above normal weight, with a steady numerical decrease in occurrence. Likewise, induction of labor was strongly associated with BMI, the prevalence ranged from $8 \%$ in the normal weight group to 25\% among the obese class III (adjusted OR 3.43 (95\% CI 2.25-5.23)). The chance of having a normal VD decreased with increasing BMI, reaching an ultimate decrease of about $40-50 \%$ in all subgroups of obese adolescents. Concurrently, the risk of CS increased with increasing BMI. However, this was only attributed to an increased risk for acute CS with increasing BMI whereas the risk of elective CS remained unchanged in the BMI groups. The absolute rate for acute CS was $4.5 \%$ among the normal weight adolescents and $16.7 \%$ in obesity class III (adjusted OR 3.00 (95\% CI 1.71-5.27)). Even the risk of having PPH>1000 ml was significantly higher in the obesity classes, independent of mode of delivery (VD or 
CS). In the VD group this increase was found already among the overweight adolescents. Neither the prevalence of instrumental VD nor the occurrence of OASI or the placental disorders, abruptio placentae and placenta previa, were influenced by increasing BMI among adolescents.

The adjusted mean gestational age in the BMI groups is illustrated in Figure 1. The risk of post-term birth (GA at delivery $\geq 42$ weeks) was significantly increased in overweight and obese adolescents by 36\% and up to 59\%, respectively. Preeclampsia also occurred significantly more often in overweight and obese adolescents compared with the normal weight adolescents (1.8\% and 1.7\%, respectively compared with 1.1\%). Although stillbirth was a rare event, with a prevalence of $0.2 \%$ in normal weight adolescents, it occurred significantly more frequently with rising BMI, reaching an 8-fold increased risk in obesity class III.

Table 4 presents the results of the unadjusted analyses of the comparisons of obstetric outcomes between the BMI groups of adolescents and the standard women. Compared with standard women, overweight adolescents have a 53\% increased chance of a normal VD (82\% vs. $75 \%$ ), almost $20 \%$ decreased risk for a CS (10.2\% vs. $12.3 \%$ ) and $25 \%$ lower risk for PPH $>1000 \mathrm{ml}$ in $\operatorname{VD}(\mathbf{4 . 5 \%}$ vs. $\mathbf{5 . 9 \%})$. Adolescents in both the overweight and the obesity classes have more than $60 \%$ decreased risk for OASI and around $40 \%$ lower risk for instrumental VD than the standard women. Obese adolescents in all three obesity classes have the same chance of having normal VD and no increased risk for PPH > $1000 \mathrm{ml}$ in VD, than the standard women. 


\section{Discussion}

The results of this large nationwide population-based study showed several adverse obstetric outcomes related to overweight and obesity among adolescents compared with their normal weight counterparts. For preeclampsia, stillbirth, post term delivery, spontaneous onset of labor, induction of labor, normal VD, CS and PPH outcomes worsened with rising BMI. Interestingly, despite risks associated with overweight and obesity in adolescents, these groups, in some respects, had better delivery and postpartum outcomes than standard women. Obese and morbidly obese adolescents had the same chance for a normal VD, no increased risk for PPH in VD and a decreased risk for instrumental delivery and OASI than standard women. The approach of risk assessment comparing the adolescents with standard women has to our knowledge not been presented before.

There are still issues of great concern comparing adolescents over the BMI strata highlighted by this study. Consistently with results of other studies is the increased risk for CS seen among overweight and obese adolescents. ${ }^{7,8}$ The risk was almost exclusively attributed to acute CS. Obesity increases the risk of anesthetic- and postoperative complications, which implies that acute CS in obese women should be restricted to cases with clear medical indications. ${ }^{22,23}$

The present study also showed that the risk for PPH in obese adolescents increased in VD and CS. Halloran et al. showed an almost 2-fold increased risk for PPH overall among black obese teenagers, whereas Haeri et al. did not find any association between PPH and BMI. ${ }^{8,9}$ A possible explanation for the increased risk of major bleeding among obese adolescents could be uterine atony. In adult obese women, the use of preventive uterotonics has been suggested..$^{4,24}$

In adolescents, being overweight and obese had an increased risk for stillbirth, and the risk increased with rising BMI. To our knowledge, this is the first study to look at this 
relatively rare, but devastating outcome of pregnancy in adolescents. The reason for this effect is not clear and merits further investigation.

The risk of preterm birth was elevated across all BMI strata in adolescents and increased with higher BMI compared with standard women. Our results did not support a positive effect on prematurity among overweight and obese adolescents as was shown concerning spontaneous onset of labor in earlier studies., ${ }^{9,11,12}$ Although the adjusted mean gestational age varied statistically significantly between the BMI groups, the differences were less than four days and consequently without any clinical relevance.

For OASI, the present study showed, in line with earlier study ${ }^{7}$, no association with obesity among adolescents. Interestingly, the risk estimates did not differ substantially after including birth weight as a covariate. Further, compared with standard women, the study showed that obese adolescents have considerable lower risk for OASI. The reasons for this positive outcome are unknown. One theory can be biological, with more favorable pelvic soft tissue factors such as more elastic properties in younger women. ${ }^{25}$

There are some strengths as well as limitations of this study. The study is nationwide, which implies that the results can be generalized to facilities with similar health care and socioeconomic conditions. Sweden has a relatively homogeneous population and a welldeveloped social security system with cost-free maternity health care and standardized registration during pregnancy and delivery.

The large validated data set made it possible to perform risk assessments even for rare complications such as stillbirth and shoulder dystocia. Despite the large data set the number of subjects in obesity class III was limited and therefore interpretations of the results in this group should be made with caution. The probability that diagnoses could be over- or underreported in registers is a well-known limitation of a register study. However, in this 
study outcomes are unlikely to vary with maternal BMI and consequently do not influence the results.

A number of potential confounding factors were adjusted for in this study, but it is possible that unknown factors might have affected the results. If available, maternal ethnicity and socioeconomic status would have been included in the adjusted analysis but this information is not available in the SMBR. The vast majority of Swedish women are Caucasian and the socioeconomic differences are moderate. Prenatal and delivery care is free for everyone. Smoking, a confounding factor adjusted for in the present study, could to some extent be looked upon as a proxy for socioeconomic status.

The main purpose of the present study was to evaluate outcomes in the groups of overweight and obese adolescents, compared with the normal weight group, not to demonstrate a potential causality between obesity and specific outcomes. Usually, this approach is considered of benefit for clinicians dealing with these women. This way of thinking led us to perform a comparison between overweight and obese adolescents and a clinically well-defined group of adult low risk women, here called standard women. This new approach showed that a number of outcomes in the overweight and obese groups of adolescents were less likely to occur than in the group of standard women. We believe that the information from this comparison could also be helpful for basic clinical care in risk scoring in the delivery ward. There is no available scientific definition of standard women, which could be considered as a shortcoming.

\section{Conclusions}

In conclusion, overweight and obesity in adolescents impaired the precondition for a favorable obstetric outcome. Obese adolescents had additional risks of increased rates of induction of labor, CS and still birth compared with both normal weight adolescents and standard women. PPH in adolescents was, compared with standard women, increased in obese 
adolescents in the setting of CS only. The reasons for the association between CS and PPH cannot be elucidated by the present study design but might probably be related to the higher rates of induction of labor. However, it is important to know that when entering the labor ward the overweight adolescent seems to have better delivery and postpartum outcomes compared with what is expected for the group of healthy normal weight adult women, who, in most delivery units, are classified as women with low obstetric risks. With the growing population of overweight and obese pregnant adolescents and adults, this is something to consider when making risk assessments to optimize the use of resources for women during pregnancy and in labor.

Author Disclosure Statement: No competing financial interests exist. 


\section{References}

1. Baeten JM, Bukusi EA, Lambe M. Pregnancy complications and outcomes among overweight and obese nulliparous women. Am J Public Health 2001;91:436-40.

2. Cnattingius S, Villamor E, Johansson S, et al. Maternal obesity and risk of preterm delivery. JAMA 2013;309:2362-70.

3. Cedergren M. Maternal Morbid Obesity and Risk of Adverse Pregnancy Outcome. Obstet Gynecol 2004;103:219-24.

4. Blomberg M. Maternal obesity and risk of postpartum hemorrhage. Obstet Gynecol 2011;118:561-8.

5. Weiss JL, Malone FD, Emig D, et al. Obesity, obstetric complications and cesarean delivery rate- A population-based screening study. Am J Obstet Gynecol 2004;190:10917.

6. Triunfo S, Lanzone A. Impact of overweight and obesity on obstetric outcomes. J Endocrinol Invest 2014;37:323-9.

7. Sukalich S, Mingione MJ, Glantz JC. Obstetric outcomes in overweight and obese adolescents. Am J Obstet Gynecol 2006;195:851-5.

8. Halloran DR, Marshall NE, Kunovich RM, Caughey AB. Obesity trends and perinatal outcomes in black and white teenagers. Am J Obstet Gynecol 2012;207:492.e1-7.

9. Haeri S, Guichard I, Baker AM, Saddlemire S, Boggess KA. The effect of teenage maternal obesity on perinatal outcomes. Obstet Gynecol 2009;113:300-4.

10. Aliyu MH, Luke, S, Kristensen S, Alio AP, Salihu HM. Joint Effect of Obesity and teenage Pregnancy on the Risk of Preeclampsia: A Population-Based Study. J Adolesc Health 2010;46:77-82. 
11. Salihu HM, Luke S, Alio AP, Deutch A, Marty PJ. The impact of obesity on spontaneous and medically indicated preterm birth among adolescent mothers. Arch Gynecol Obstet 2010;282:127-34.

12. Baker AM, Haeri S. Estimating risk factors for spontaneous preterm delivery in teen pregnancies. Arch Gynecol Obstet 2014;289:1203-6.

13. Braine T. Adolescent pregnancy: a culturally complex issue. Bull World Health Organ 2009;87:410-1.

14. Ogden CL, Carrol MD, Kit BK, Flegal KM. Prevalence of Obesity and Trends in Body Mass Index Among US Children and Adolescents. JAMA 2012;307:48390.doi:10.1001/jama.2012.40.

15. Vienne C M, Creveuil C, Dreyfus M. Does young maternal age increase the risk of adverse obstetric, fetal and neonatal outcomes: A cohort study. Eur J Obstet Gynecol Reprod Biol 2009;147:151-56.

16. Gupta N, Kiran U, Bhal K. Teenage pregnancies: Obstetric Characteristics and outcome. Eur J Obstet Gynecol Reprod Biol 2008;137:165-71.

17. Blomberg M, Birch Tyrberg R, Kjølhede P. Impact of maternal age on obstetric and neonatal outcome with emphasis on primiparous adolescents and older women: a Swedish Medical Birth Register Study. BMJ Open 2014;4:e005840.

18. Blomberg M. Avoiding the first cesarean section-results of structured organizational and cultural changes. Acta Obstet Gynecol Scand 2016;95:580-6.

19. Källen B, Källen K, Olausson PO. The Swedish Medical Birth Register: a summary of content and quality. Research Report, Article no: 2003-112-3. Centre for Epidemiology, National Board of Health and Welfare Stockholm, 2003. http://www.socialstyrelsen.se/publikationer2003/2003-112-3 (Accessed Feb 2016). 
20. Cnattingius S, Ericson A, Gunnarskog J, Källen B. A quality study of a medical birth registry. Scand J Soc Med 1990;18:143-8.

21. Axelsson O. The Swedish medical birth register. Acta Obstet Gynecol Scand 2003;82:491-2.

22. Vricella LK, Louis JM, Mercer BM, Bolden N. Anesthesia complications during scheduled cesarean delivery for morbidly obese women. Am J Obstet Gynecol 2010;203:276.e1-5.

23. Ayres-de-Campos D. Obesity and the challenges of caesarean delivery: Prevention and management of wound complications. Best Pract Res Clin Obstet Gynaecol 2015;29:40614.

24. Wetta LA, Szychowski JM, Seals S, Mancuso MS, Biggio JR, Tita AT. Risk factors for uterine atony/postpartum hemorrhage requiring treatment after vaginal delivery. Am J Obstet Gynecol 2013;209:51.e1-6.

25. Chantereau P, Brieu M, Kammal M, Farthmann J, Gabriel B, Cosson M. Mechanical properties of pelvic soft tissue of young women and impact of aging. Int Urogynecol $\mathrm{J}$ 2014;25:1547-53. doi: 10.1007/s00192-014-2439-1. Epub 2014 Jul 10. 
ANOVA: $F(3,30777)=31.431$,

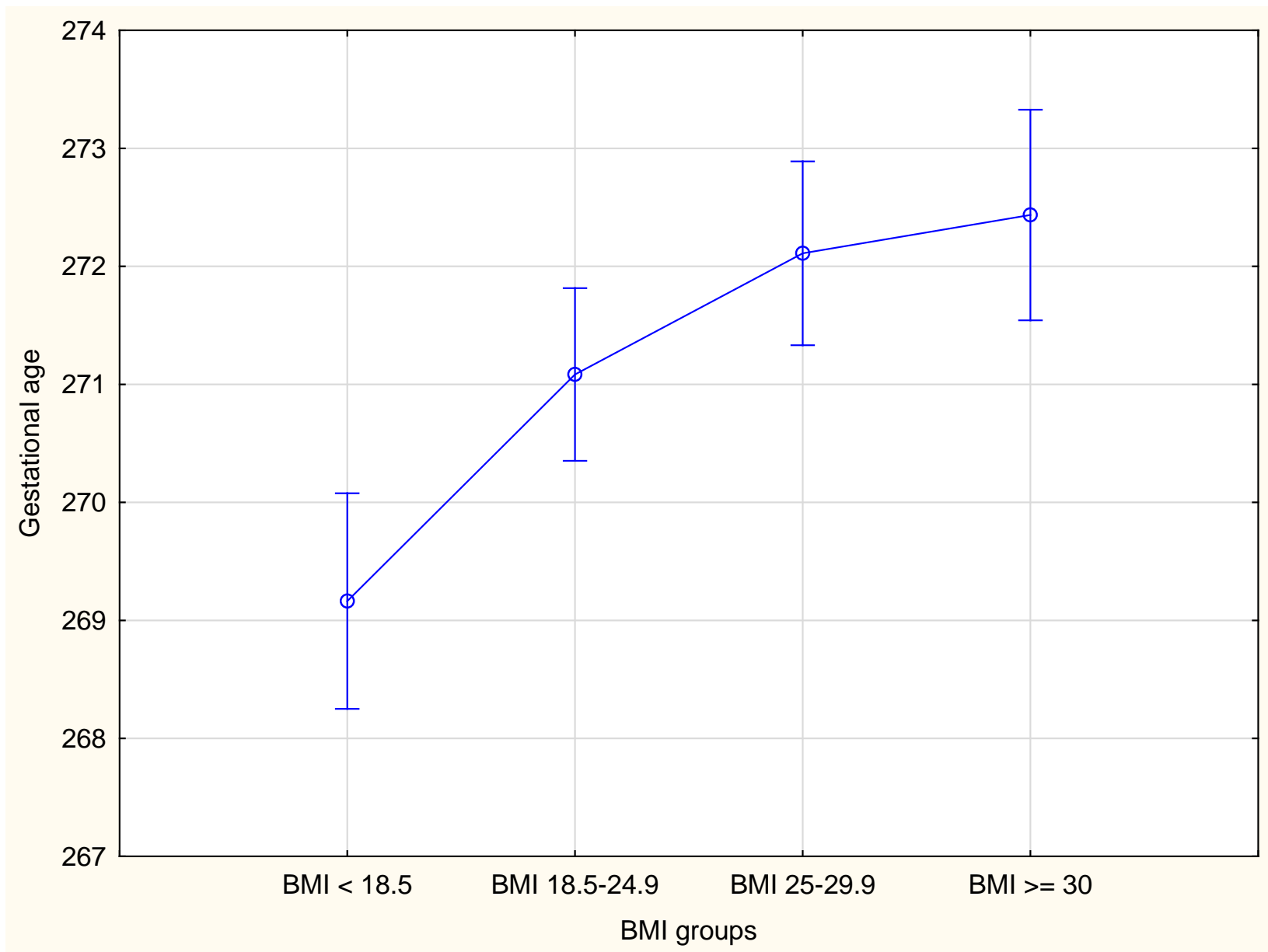

Figure 1. Gestational age in relation to BMI groups of adolescents. Adjusted for smoking habits, preeclampsia and maternal co-morbidity. Plots indicate mean gestational age and bars indicate 95\% confidence interval. 
Table 1. Demographic and descriptive data of primiparous adolescents according to body mass index (BMI).

\begin{tabular}{|c|c|c|c|c|c|c|c|}
\hline & \multicolumn{4}{|c|}{$\mathrm{BMI}\left(\mathrm{kg} / \mathrm{m}^{2}\right)$} & \multicolumn{3}{|c|}{ Obesity (BMI $\geq 30$ ) subdivided into three classes } \\
\hline & $\begin{array}{c}<18.5 \\
n=2271\end{array}$ & $\begin{array}{c}18.5-24.9 \\
n=20719\end{array}$ & $\begin{array}{c}25.0-29.9 \\
n=6109\end{array}$ & $\begin{array}{c}\geq 30.0 \\
n=2287\end{array}$ & $\begin{array}{c}30.0-34.9 \\
n=1734\end{array}$ & $\begin{array}{c}35.0-39.9 \\
n=433\end{array}$ & $\begin{array}{l}\geq 40.0 \\
n=120\end{array}$ \\
\hline \multicolumn{8}{|l|}{ Maternal age (years) } \\
\hline 17 & $351(15 \%)$ & $2986(14 \%)$ & $801(13 \%)$ & $234(10 \%)$ & $185(11 \%)$ & $39(9 \%)$ & $10(8 \%)$ \\
\hline 18 & $587(26 \%)$ & $5439(26 \%)$ & $1638(27 \%)$ & $594(26 \%)$ & $437(25 \%)$ & $117(27 \%)$ & 40 (34\%) \\
\hline 19 & $1175(52 \%)$ & $10718(52 \%)$ & $3253(53 \%)$ & $1339(59 \%)$ & $1012(58 \%)$ & $262(61 \%)$ & $65(54 \%)$ \\
\hline$<10$ cig/day & $568(25 \%)$ & $4703(23 \%)$ & $1382(23 \%)$ & $576(25 \%)$ & $421(24 \%)$ & $118(27 \%)$ & $37(31 \%)$ \\
\hline$\geq 10 \mathrm{cig} / \mathrm{day}$ & $145(6 \%)$ & $1354(6 \%)$ & $350(6 \%)$ & $202(9 \%)$ & $153(9 \%)$ & $38(9 \%)$ & $11(9 \%)$ \\
\hline Missing data & $45(2 \%)$ & $396(2 \%)$ & $96(1 \%)$ & $41(2 \%)$ & $29(2 \%)$ & $10(2 \%)$ & $2(2 \%)$ \\
\hline \multicolumn{8}{|l|}{ Comorbidity* } \\
\hline Diabetes Mellitus & $1(0.0 \%)$ & $45(0.2 \%)$ & $32(0.5 \%)$ & $15(0.7 \%)$ & $10(0.6 \%)$ & $3(0.7 \%)$ & $2(1.7 \%)$ \\
\hline Hypertension & $2(0.1 \%)$ & $17(0.1 \%)$ & $5(0.1 \%)$ & $7(0.3 \%)$ & $5(0.3 \%)$ & $2(0.5 \%)$ & 0 \\
\hline
\end{tabular}

Figures denote counts and proportions.

SLE, systemic lupus erythematosus

*Maternal smoking and comorbidity reported at the first antenatal visit. 
Table 2. Obstetric characteristics of the primiparous adolescents according to body mass index (BMI) and primiparous standard women.

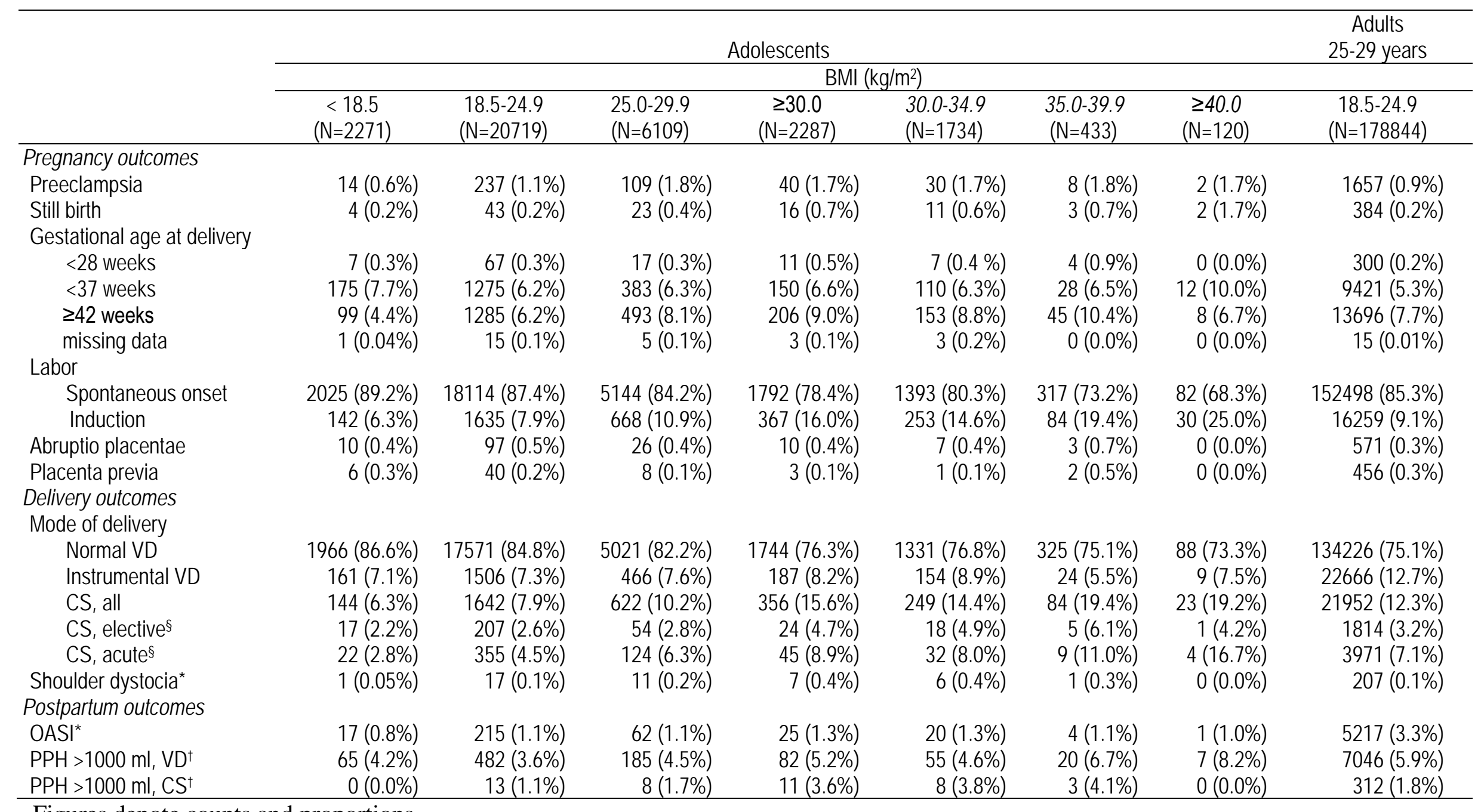

Figures denote counts and proportions. 
CS, Cesarean section; OASI, obstetric anal sphincter injury; PPH, postpartum hemorrhage; SMBR, Swedish Medical Birth Register; VD, vaginal delivery.

${ }^{\S} \mathrm{CS}$, elective and acute registered in SMBR from 1999.

*Shoulder dystocia and OASI only in vaginal deliveries. ${ }^{\dagger}$ PPH registered in SMBR from 1997. 
Table 3. Obstetric outcomes of primiparous adolescents with singleton births according to body mass index (BMI).

\begin{tabular}{|c|c|c|c|c|c|c|c|c|c|c|}
\hline \multirow[b]{2}{*}{$\mathrm{BMI}\left(\mathrm{kg} / \mathrm{m}^{2}\right)$} & \multirow[b]{2}{*}{$\begin{array}{c}\text { Mode of } \\
\text { OR }\end{array}$} & \multicolumn{2}{|c|}{ Pregnancy condition } & \multicolumn{3}{|c|}{ Gestational age (GA) at delivery } & \multicolumn{2}{|c|}{ Onset of labor } & \multicolumn{2}{|c|}{ Placental disorder } \\
\hline & & Preeclampsia & Still birth & $<28$ weeks & $<37$ weeks & $\geq 42$ weeks & Spontaneous & Induction & $\begin{array}{l}\text { Abruptio } \\
\text { placentae }\end{array}$ & Placenta previa \\
\hline \multirow{2}{*}{$<18.5$} & Crude & $0.54(0.31-0.92)$ & $0.85(0.30-2.37)$ & $0.95(0.44-2.08)$ & $1.27(1.08-1.50)$ & $0.70(0.56-0.85)$ & $1.20(1.03-1.39)$ & $0.78(0.65-0.93)$ & $0.94(0.49-1.81)$ & $1.37(0.58-3.23)$ \\
\hline & Adjusted* & $0.58(0.33-1.01)$ & $0.86(0.31-2.40)$ & $0.84(0.36-1.94)$ & $1.28(1.09-1.52)$ & $0.68(0.55-0.84)$ & $1.22(1.05-1.42)$ & $0.76(0.64-0.91)$ & $0.86(0.43-1.71)$ & $1.48(0.62-3.50)$ \\
\hline \multirow{2}{*}{$25.0-29.9$} & Crude & $1.57(1.25-1.97)$ & $1.82(1.09-3.02)$ & $0.86(0.50-1.47)$ & $1.02(0.90-1.15)$ & $1.33(1.19-1.48)$ & $0.74(0.68-0.80)$ & $1.43(1.30-1.57)$ & $0.91(0.59-1.40)$ & $0.68(0.32-1.45)$ \\
\hline & Adjusted* & $1.83(1.43-2.33)$ & $1.86(1.12-3.10)$ & $0.77(0.44-1.35)$ & $0.99(0.88-1.12)$ & $1.36(1.22-1.52)$ & $0.77(0.71-0.84)$ & $1.37(1.24-1.50)$ & $0.96(0.62-1.48)$ & $0.80(0.37-1.72)$ \\
\hline \multirow{2}{*}{$\geq 30.0$} & Crude & $1.54(1.10-2.16)$ & $3.39(1.91-6.02)$ & $1.49(0.79-2.82)$ & $1.07(0.90-1.28)$ & $1.50(1.28-1.75)$ & $0.49(0.44-0.55)$ & $2.23(1.97-2.52)$ & $0.93(0.49-1.79)$ & $0.68(0.21-2.20)$ \\
\hline & Adjusted* & $2.33(1.62-3.36)$ & $3.17(1.74-5.77)$ & $1.48(0.77-2.83)$ & $1.03(0.86-1.23)$ & $1.59(1.36-1.86)$ & $0.55(0.49-0.62)$ & $2.04(1.80-2.31)$ & $0.91(0.45-1.81)$ & $0.99(0.30-3.22)$ \\
\hline \multirow{2}{*}{$30.0-34.9$} & Crude & $1.52(1.04-2.23)$ & $3.07(1.58-5.97)$ & $1.25(0.57-2.73)$ & $1.03(0.85-1.26)$ & $1.47(1.23-1.75)$ & $0.56(0.49-0.63)$ & $1.99(1.73-2.30)$ & $0.86(0.40-1.86)$ & $0.30(0.00-2.17)$ \\
\hline & Adjusted* & $2.31(1.53-3.47)$ & $2.78(1.38-5.60)$ & $1.24(0.57-2.73)$ & $1.00(0.81-1.22)$ & $1.55(1.29-1.85)$ & $0.61(0.54-0.70)$ & $1.84(1.59-2.12)$ & $0.79(0.34-1.81)$ & $0.42(0.06-3.06)$ \\
\hline \multirow{2}{*}{$35.0-39.9$} & Crude & $1.63(0.80-3.31)$ & $3.35(1.04-10.9)$ & $2.87(1.04-7.91)$ & $1.05(0.72-1.55)$ & $1.75(1.28-2.40)$ & $0.37(0.29-0.46)$ & $2.82(2.21-3.60)$ & $1.48(0.47-4.70)$ & $2.40(0.58-9.96)$ \\
\hline & Adjusted* & $2.58(1.16-5.75)$ & $3.36(1.03-10.98)$ & $2.85(1.03-7.94)$ & $1.04(0.70-1.53)$ & $1.88(1.37-2.58)$ & $0.42(0.34-0.53)$ & $2.53(1.98-3.25)$ & $1.63(0.51-5.21)$ & $3.91(0.93-16.52)$ \\
\hline \multirow{2}{*}{$\geq 40$} & Crude & $1.46(0.36-5.96)$ & $8.15(1.95-34.0)$ & $N / A$ & $1.69(0.93-3.08)$ & $1.08(0.53-2.22)$ & $0.26(0.19-0.43)$ & $3.91(2.58-5.94)$ & $N / A$ & $\mathrm{~N} / \mathrm{A}$ \\
\hline & Adjusted* & $1.97(0.43-8.96)$ & $8.20(1.94-34.63)$ & $N / A$ & $1.47(0.78-2.75)$ & $1.18(0.58-2.44)$ & $0.34(0.23-0.50)$ & $3.43(2.25-5.23)$ & $\mathrm{N} / \mathrm{A}$ & $\mathrm{N} / \mathrm{A}$ \\
\hline
\end{tabular}


Table 3 continued. Obstetric outcomes of primiparous adolescents with singleton births according to body mass index (BMI).

\begin{tabular}{|c|c|c|c|c|c|c|c|c|c|c|}
\hline \multirow[b]{2}{*}{$\mathrm{BMI}\left(\mathrm{kg} / \mathrm{m}^{2}\right)$} & \multirow[b]{2}{*}{$\begin{array}{c}\text { Mode of } \\
\text { OR }\end{array}$} & \multicolumn{2}{|c|}{ Vaginal delivery (VD) } & \multicolumn{3}{|c|}{ Cesarean section (CS) } & \multicolumn{4}{|c|}{ Obstetric complications } \\
\hline & & Normal & Instrumental & All & Elective $^{\S}$ & Acute $^{\S}$ & $\begin{array}{l}\text { Shoulder } \\
\text { dystocia }{ }^{*}\end{array}$ & OASI & $\begin{array}{c}\mathrm{PPH}>1000 \mathrm{ml} \\
\mathrm{VD}^{\dagger}\end{array}$ & $\begin{array}{c}\mathrm{PPH}>1000 \mathrm{ml} \\
\mathrm{CS}^{\dagger}\end{array}$ \\
\hline \multirow{2}{*}{$<18.5$} & Crude & $1.15(1.02-1.31)$ & $0.97(0.82-1.15)$ & $0.79(0.66-0.94)$ & $1.12(0.82-1.54)$ & $0.69(0.53-0.91)$ & $0.53(0.07-3.96)$ & $0.72(0.44-1.18)$ & $1.16(0.89-1.51)$ & $\mathrm{N} / \mathrm{A}$ \\
\hline & Adjusted* & $1.15(1.01-1.30)$ & $0.99(0.83-1.17)$ & $0.73(0.61-0.87)$ & $1.07(0.77-1.48)$ & $0.66(0.51-0.87)$ & $0.88(0.12-6.70)$ & $0.82(0.50-1.36)$ & $1.15(0.88-1.50)$ & $\mathrm{N} / \mathrm{A}$ \\
\hline \multirow{2}{*}{$25.0-29.9$} & Crude & $0.83(0.77-0.89)$ & $1.05(0.95-1.17)$ & $1.32(1.20-1.45)$ & $1.01(0.82-1.26)$ & $1.42(1.24-1.62)$ & $2.25(1.05-4.81)$ & $0.98(0.74-1.30)$ & $1.25(1.05-1.49)$ & $1.56(0.64-3.78)$ \\
\hline & Adjusted* & $0.85(0.79-0.92)$ & $1.04(0.93-1.16)$ & $1.32(1.19-1.46)$ & $1.04(0.83-1.30)$ & $1.43(1.25-1.64)$ & $1.42(0.63-3.18)$ & $0.80(0.59-1.06)$ & $1.23(1.04-1.47)$ & $1.47(0.60-3.59)$ \\
\hline \multirow{2}{*}{$\geq 30.0$} & Crude & $0.58(0.52-0.64)$ & $1.14(0.97-1.33)$ & $2.14(1.89-2.42)$ & $1.31(0.99-1.73)$ & $2.37(2.02-2.78)$ & $2.08(1.69-9.85)$ & $1.05(0.70-1.60)$ & $1.46(1.15-1.85)$ & $3.40(1.51-7.66)$ \\
\hline & Adjusted* & $0.61(0.55-0.68)$ & $1.11(0.95-1.31)$ & $2.11(1.85-2.40)$ & $1.25(0.93-1.67)$ & $2.45(2.08-2.88)$ & $2.41(0.95-6.12)$ & $0.81(0.53-1.24)$ & $1.39(1.09-1.78)$ & $3.44(1.51-7.83)$ \\
\hline \multirow{2}{*}{$30.0-34.9$} & Crude & $0.59(0.53-0.67)$ & 1.24 (1.05-1.48) & $1.95(1.69-2.25)$ & $1.23(0.89-1.70)$ & $2.16(1.80-2.59)$ & $4.55(1.79-11.6)$ & $1.11(0.70-1.76)$ & $1.28(0.96-1.70)$ & 3.57 (1.46-8.71) \\
\hline & Adjusted* & $0.62(0.55-0.69)$ & $1.23(1.04-1.47)$ & $1.96(1.69-2.28)$ & $1.21(0.87-1.70)$ & $2.25(1.86-2.71)$ & $2.88(1.09-7.58)$ & $0.87(0.54-1.39)$ & $1.24(0.93-1.66)$ & $3.47(1.41-8.54)$ \\
\hline \multirow{2}{*}{$35.0-39.9$} & Crude & $0.54(0.43-0.67)$ & $0.75(0.49-1.13)$ & $2.80(2.19-3.57)$ & $1.65(0.97-2.80)$ & $3.03(2.25-4.07)$ & $3.22(0.43-24.3)$ & $0.89(0.33-2.40)$ & $1.93(1.21-3.06)$ & $3.86(1.08-13.9)$ \\
\hline & Adjusted* & $0.61(0.48-0.76)$ & $0.68(0.44-1.05)$ & $2.61(2.01-3.38)$ & $1.42(0.80-2.52)$ & $3.10(2.28-4.21)$ & $1.73(0.22-13.45)$ & $0.68(0.25-1.85)$ & $1.77(1.10-2.85)$ & $4.25(1.16-15.6)$ \\
\hline \multirow{2}{*}{$\geq 40$} & Crude & $0.49(0.33-0.74)$ & $1.03(0.52-2.04)$ & $2.75(1.74-4.35)$ & $1.19(0.38-3.8)$ & $3.02(1.73-5.26)$ & $N / A$ & $0.80(0.11-5.76)$ & $2.39(1.10-5.21)$ & $\mathrm{N} / \mathrm{A}$ \\
\hline & Adjusted* & $0.52(0.35-0.79)$ & $1.02(0.52-2.02)$ & $2.51(1.57-4.04)$ & $1.09(0.34-3.50)$ & $3.00(1.71-5.27)$ & $\mathrm{N} / \mathrm{A}$ & $0.54(0.07-3.95)$ & $2.29(1.05-5.00)$ & $\mathrm{N} / \mathrm{A}$ \\
\hline
\end{tabular}

N/A, not applicable; OASI, obstetric anal sphincter injury; PPH, postpartum hemorrhage; SMBR, Swedish Medical Birth Register.

Figures denote odds ratios with 95\% confidence intervals. Reference group: Adolescents with BMI 18.5- 24.9

*Adjusted for smoking in early pregnancy, calendar year of the delivery, maternal age and maternal comorbidity. Preeclampsia and CS also adjusted for GA. GA also adjusted for preeclampsia. Shoulder dystocia and OASI also adjusted for birth weight.

${ }^{\S} \mathrm{CS}$, elective and acute registered in SMBR from 1999. \#Only vaginal deliveries.

${ }^{\dagger} \mathrm{PPH}$ registered in SMBR from 1997. 
Table 4. Obstetric outcomes of primiparous adolescents with singleton births according to body mass index (BMI) compared with standard women.

\begin{tabular}{|c|c|c|c|c|c|c|c|c|c|}
\hline \multirow[b]{2}{*}{ BMI $\left(\mathrm{kg} / \mathrm{m}^{2}\right)$} & \multicolumn{2}{|c|}{ Pregnancy condition } & \multicolumn{3}{|c|}{ Gestational age at delivery } & \multicolumn{2}{|c|}{ Onset of labor } & \multicolumn{2}{|c|}{ Placental disorder } \\
\hline & Preeclampsia & Still birth & $<28$ weeks & $<37$ weeks & $\geq 42$ weeks & Spontaneous & Induction & $\begin{array}{l}\text { Abruptio } \\
\text { placentae }\end{array}$ & Placenta previa \\
\hline$<18.5$ & $0.66(0.39-1.12)$ & $0.82(0.31-2.20)$ & $1.84(0.87-3.90)$ & $1.50(1.29-1.75)$ & $0.55(0.45-0.67)$ & $1.49(1.29-1.71)$ & $0.67(0.56-0.79)$ & $1.38(0.74-2.58)$ & $1.04(0.46-2.32)$ \\
\hline $18.5-24.9$ & $1.24(1.08-1.42)$ & $0.97(0.70-1.33)$ & $1.93(1.48-2.52)$ & $1.18(1.11-1.25)$ & $0.80(0.75-0.85)$ & $1.24(1.19-1.13)$ & $0.86(0.81-0.91)$ & $1.47(1.18-1.82)$ & $0.76(0.55-1.05)$ \\
\hline $25.0-29.9$ & $1.94(1.60-2.36)$ & $1.76(1.15-2.68)$ & $1.66(1.02-2.71)$ & $1.20(1.08-1.34)$ & $1.06(0.96-1.16)$ & $0.91(0.85-0.98)$ & $1.23(1.13-1.33)$ & $1.33(0.09-1.98)$ & $0.51(0.25-1.03)$ \\
\hline$\geq 30.0$ & $1.90(1.39-2.61)$ & $3.27(1.98-5.41)$ & $2.88(1.58-5.26)$ & $1.26(1.07-1.49)$ & $1.20(1.03-1.38)$ & $0.61(0.55-0.68)$ & $1.92(1.71-2.15)$ & $1.37(0.73-2.57)$ & $0.51(0.16-1.60)$ \\
\hline $30.0-34.9$ & $1.88(1.31-2.71)$ & $2.97(1.63-5.41)$ & $2.42(1.14-5.12)$ & $1.22(1.00-1.48)$ & $1.17(0.99-1.38)$ & $0.69(0.61-0.78)$ & $1.71(1.50-1.96)$ & $1.27(0.60-2.67)$ & $0.23(0.03-1.61)$ \\
\hline $35.0-39.9$ & $2.01(1.00-4.06)$ & $3.24(1.04-10.1)$ & $5.55(2.06-14.9)$ & $1.24(0.85-1.82)$ & $1.40(1.03-1.90)$ & $0.46(0.37-0.57)$ & $2.42(1.91-3.07)$ & $2.18(0.70-6.80)$ & $1.82(0.45-7.30)$ \\
\hline$\geq 40$ & $1.81(0.45-7.34)$ & $7.88(1.94-32.0)$ & $\mathrm{N} / \mathrm{A}$ & $2.00(1.10-3.63)$ & $0.86(0.42-1.76)$ & $0.36(0.24-0.53)$ & $3.36(2.22-5.09)$ & $\mathrm{N} / \mathrm{A}$ & $\mathrm{N} / \mathrm{A}$ \\
\hline
\end{tabular}

Table 4 continued. Obstetric outcomes of primiparous adolescents with singleton births according to body mass index (BMI) compared with standard women.

\begin{tabular}{|c|c|c|c|c|c|c|c|c|c|}
\hline \multirow[b]{2}{*}{$\begin{array}{c}\mathrm{BMI} \\
\left(\mathrm{kg} / \mathrm{m}^{2}\right)\end{array}$} & \multicolumn{2}{|c|}{ Vaginal delivery (VD) } & \multicolumn{3}{|c|}{ Cesarean section (CS) } & \multicolumn{4}{|c|}{ Obstetric complications } \\
\hline & Normal & al & All & Elective $^{\S}$ & Acute $^{\S}$ & $\begin{array}{l}\text { Shoulder } \\
\text { dystocia } \#\end{array}$ & OASI & $\begin{array}{c}\mathrm{PPH}>1000 \mathrm{ml} \\
\mathrm{VD}^{\dagger}\end{array}$ & $\begin{array}{c}\mathrm{PPH}>1000 \mathrm{ml} \\
\mathrm{CS}^{\dagger}\end{array}$ \\
\hline$<18.5$ & $14(1.90-2.48)$ & $0.62)$ & $48(0.41-0.57)$ & $76(0.56-1.02)$ & $.42(0.32-0.54)$ & $0.36(0.05-2.54)$ & $0.23(0.15-0$ & $0.69(0.54-0.89)$ & $\mathrm{N} / \mathrm{A}$ \\
\hline $18.5-24.9$ & $1.86(1.78-1.93)$ & $-0.57)$ & $0.62(0.58-0.65)$ & & $0.60(0.55-0.65)$ & $0.68(0.41-1.11)$ & $0.33(0.29$ & $-0.66)$ & 0.61 \\
\hline $25.0-29.9$ & & $0.57(($ & & & & & & & \\
\hline$\geq 30.0$ & $1.07(0.97-1.18)$ & $.61(0.53-0.71)$ & $1.32(1.18-1.48)$ & $0.88(0.68-1.14)$ & $1.42(1.23-1.63)$ & $2.75(1.29-5.86)$ & $0.38(0.26-0.57)$ & $0.87(0.70-1.09)$ & 2.08 (1.13-3.83) \\
\hline $30.0-34.9$ & & $0.67(0.57-0.79)$ & & & & $3.07(1.36-6$ & & & \\
\hline $35.0-39.9$ & $1.00(0.80-1.24)$ & $0.40(0.27-0.61)$ & $1.72(1.36-2.18)$ & $1.11(0.66-1.87)$ & $1.81(1.36-2.42)$ & $2.18(0.30-15.6)$ & $0.34(0.13-0.90)$ & $1.15(0.73-1.82)$ & $2.36(0.74-7.53)$ \\
\hline$\geq 40$ & $0.91(0.61-1.37)$ & $0.56(0.28-1.10)$ & $1.69(1.08-2.67)$ & $0.80(0.25-2.54)$ & $1.80(1.04-3.14)$ & $\mathrm{N} / \mathrm{A}$ & $0.30(0.04-2.17)$ & $1.43(0.66-3.11)$ & $\mathrm{N} / \mathrm{A}$ \\
\hline
\end{tabular}

Figures denote crude odds ratios with 95\% confidence intervals. Reference group: Primiparous, non-smoking, healthy, normal weight adult women age 25-29 years. N/A, not applicable; OASI, obstetric anal sphincter injury; PPH, postpartum hemorrhage; SMBR, Swedish Medical Birth Register.

${ }^{\S} \mathrm{CS}$, elective and acute registered in SMBR from 1999. \#Only vaginal deliveries.

${ }^{\dagger} \mathrm{PPH}$ registered in SMBR from 1997. 
